pliegos sueltos 


\title{
Retratos del género negro en la Argentina de hoy
}

\author{
Depictions of the Noir Genre in Today's Argentina
}

Retratos de romance policial na Argentina de hoje

\section{Alejandro Meter}

UNIVERSITY OF SAN DIEGO, ESTADOS UNIDOS

Profesor en la Universidad de San Diego, California, en donde dirige el Programa de Justicia Social y enseña cursos de literatura y cultura latinoamericana. $\mathrm{PhD}$ en Literatura Latinoamericana por la Universidad de Pittsburgh. Editó Literatura judía en América Latina, un volumen especial de la Revista Iberoamericana (2001), y co-editó el libro Memoria y representación: configuraciones culturales y literarias en el imaginario judí latinoamericano (Beatriz Viterbo, 2006). También ha publicado artículos y reseñas en diversas revistas literarias. Además de la docencia y la investigación, Alejandro Meter se desempeña como fotógrafo especializado en retratos, algunos de los cuales han aparecido en diferentes periódicos y revistas, tanto en Europa como en América Latina. Correo electrónico: ameter@sandiego.edu

Archivo fotográfico

Documento accesible en línea desde la siguiente dirección: http://revistas.javeriana.edu.co doi:10.11144/Javeriana.cl21-41.rgna

Cómo citar este archivo fotográfico:

Meter, Alejandro. "Retratos del género negro en la Argentina de hoy". Cuadernos de Literatura 21.41 (2017): 315-324. https://doi.org/10.11144/Javeriana.cl21-41.rgna 
A LO LARGo del año en curso, 2016, he realizado una serie de fotografías de escritores argentinos, cronistas, cuentistas, novelistas y poetas. Cuando la revista Cuadernos de Literatura me invitó a publicar algunas de ellas, procuré organizar mi archivo alrededor de ciertos núcleos o ejes temáticos. Para esta primera entrega, me propuse reunir a nueve novelistas pertenecientes al género negro en la literatura argentina actual. Como toda selección, la lista no es exhaustiva. En cada sesión de fotos, logré conversar con los autores en sus hogares, lugares de trabajo o cafés favoritos. A continuación, se disponen las imágenes acompañadas por una breve ficha bio-bibliográfica de cada uno de ellos y una reflexión sobre cómo se indentifican con el género policial, detectivesco, o criminal, que llamamos "negro".

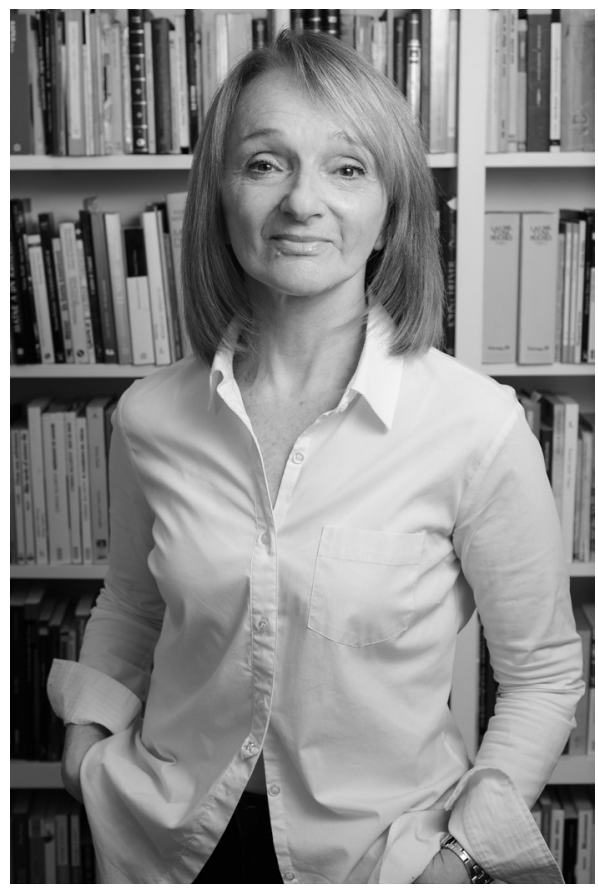

\section{María Inés Krimer}

Nació en 1951 en Paraná, Entre Ríos. Publicó Veterana (1998, cuentos), La hija de Singer (2002, novela; Primer Premio del Fondo Nacional de las Artes), El cuerpo de las chicas (2006), Lo que nosotras sabíamos (2009, novela; Premio Emecé), Sangre kosher (2010, novela, Aquilina; traducida al alemán y al italiano) y Siliconas express (2013, novela, Aquilina). En el 2011 ganó el premio Letra Sur con La inauguración. El año pasado salió Sangre Fashion, tercera parte de la saga de la detective Ruth Epelbaum, y en agosto próximo publicará Noxa, editada por Revólver. Sus relatos integran diversas antologías. Reside en Buenos Aires.

Mi vinculación con el género negro viene de las historietas que leí de chica, desde el Tony hasta Misterix. Después vinieron los policiales que papá traía de una biblioteca pública. Cuando fui convocada para escribir en Negro Absoluto volví sobre esas novelas y comprobé que mi entusiasmo por Chandler o Hammett seguía intacto. Incorporé a Goodis, a Jim Thompson, a James Cain. Y volví a confirmar que más que tramas ingeniosas me interesa leer autores. Cuando mejores sean envolverán lo no dicho con mayor sutileza: como en toda obra literaria lo importante es el tono, la musicalidad que, en última instancia, es una visión del mundo. (María Inés Krimer) 


\section{Leonardo Oyola}

Nació en 1973. Se crió en el oeste del gran Buenos Aires. Escribe policiales y le guiña un ojo a lo fantástico. Colabora en la edición argentina de la revista Rolling Stone y en Orsai, en donde entregó bimestralmente, durante el 2012, el folletín Cruz/Diablo. Cuentos suyos han sido seleccionados en varias antologías y medios gráficos de nuestro país, Uruguay, Francia, México y España. Tiene publicadas las novelas Santería y Sacrificio para la colección Negro Absoluto, que es dirigida por Juan Sasturain, además de Siete \& el Tigre Harapiento (tercera mención del Premio Clarín 2004), Hacé que la noche venga (revelación 2008 en la Revista $\tilde{\mathcal{N}})$, Bolonqui, Gólgota (traducida al francés) y Chamamé (Premio Dashiell

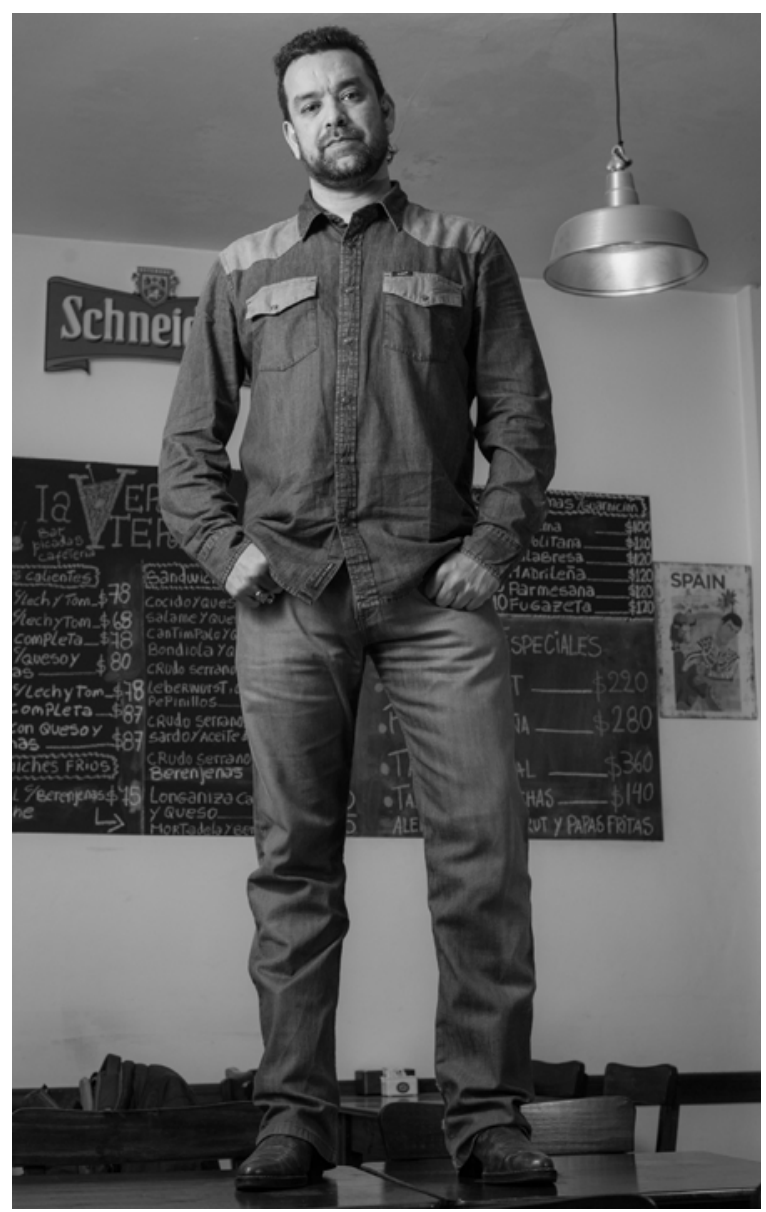
Hammett al mejor policial en la XXI Semana Negra de Gijón; también traducida al francés). Kryptonita fue elegido en una votación organizada por la librería Eterna Cadencia como el mejor libro de 2011, y llevado al cine en el 2015 por Nicanor Loreti; adaptación que contó con muy buenas críticas y que fue vista por más de 120.000 espectadores. Sus últimas publicaciones a la fecha son la novela infantil Sopapo y el libro de relatos Sultanes del ritmo. 


\section{Mercedes Giuffré}

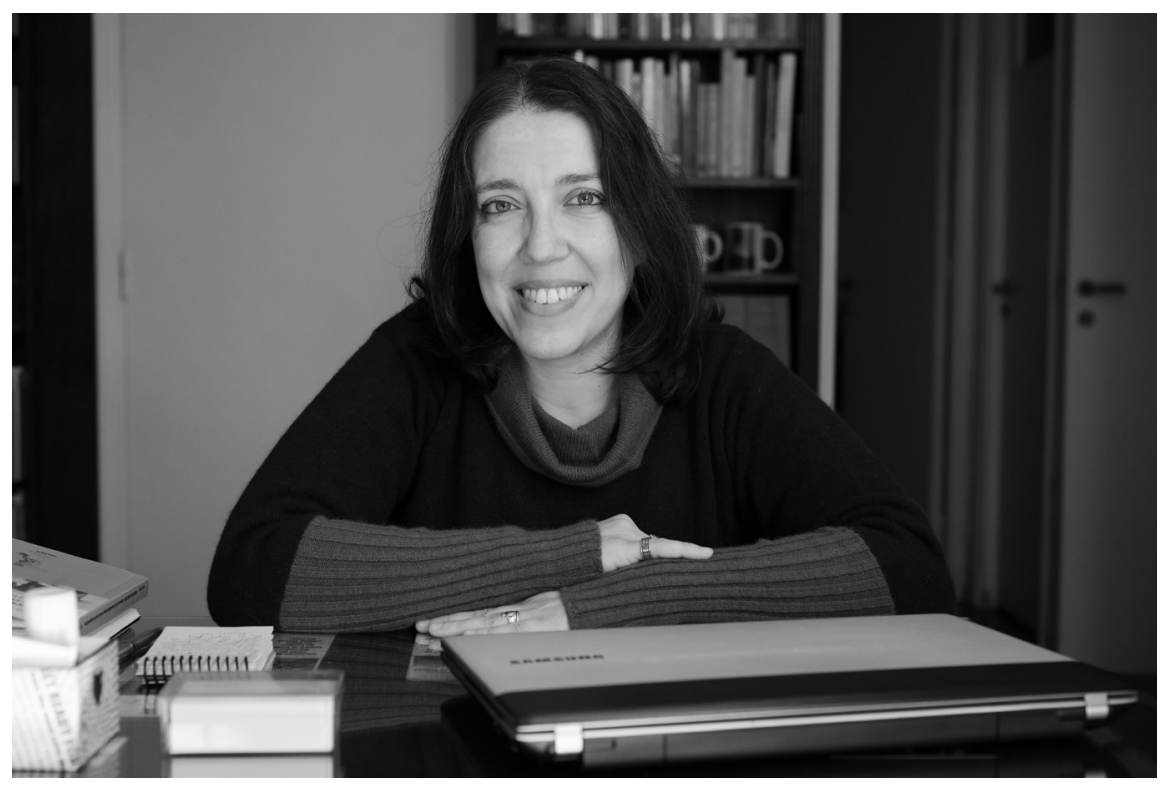

Nació en Buenos Aires en 1972. Egresó de la carrera de Letras y escribe actualmente su tesis de posgrado para la Maestría en Literaturas Española y Latinoamericana de la Universidad de Buenos Aires. Se desempeña como docente en las cátedras de Literatura Iberoamericana y el Taller de escritura creativa, en la carrera de Letras de la Facultad de Filosofía, Letras y Estudios Orientales de la USAL. Dirige el ciclo LEA de lectura y entrevistas a escritores. Es autora de los libros Lo único irremediable (2003, cuentos), En busca de una identidad, la novela histórica en Argentina (2004, ensayo), Un colono escocés (2004, biografía), Deuda de Sangre (2008, novela), El peso de la verdad (2010, novela) y El carro de la muerte (2011, novela). Las tres últimas, cuya continuación se publicará en 2017, conforman una serie policial detectivesca, ambientada en Buenos Aires durante las Invasiones Inglesas de 1806 y 1807. Es además autora de una novela inédita, Los Olvidados, que transcurre en la Segunda Guerra Mundial, en los campos de concentración vichistas, en las colonias francesas de África del Norte. 


\section{Gabriela Cabezón Cámara}

Nació en Buenos Aires en 1968. Publicó La Virgen Cabeza (2009, novela, Eterna Cadencia, Buenos Aires), Le viste la cara a Dios (nouvelle; 2011, Sigueleyendo, Barcelona; y 2012, La Isla de la Luna, Buenos Aires), Beya, le viste la cara a Dios (2013, novela gráfica ilustrada por Iñaki Echeverría; Eterna Cadencia, Buenos Aires), Romance de la Negra Rubia (2014, novela, Eterna Cadencia, Buenos Aires), Sacrificios (editado en 2015 por la Biblioteca Nacional argentina para su Colección del Bicentenario), $Y$ su despojo fue una muchedumbre (2015, relatos ilustrados por Iñaki Echeverría, Cazador de Ratas Editorial, Cádiz). En marzo de 2017 aparecerá su novela Una novela imperialista, obra que será publicada por Literatura Random House.

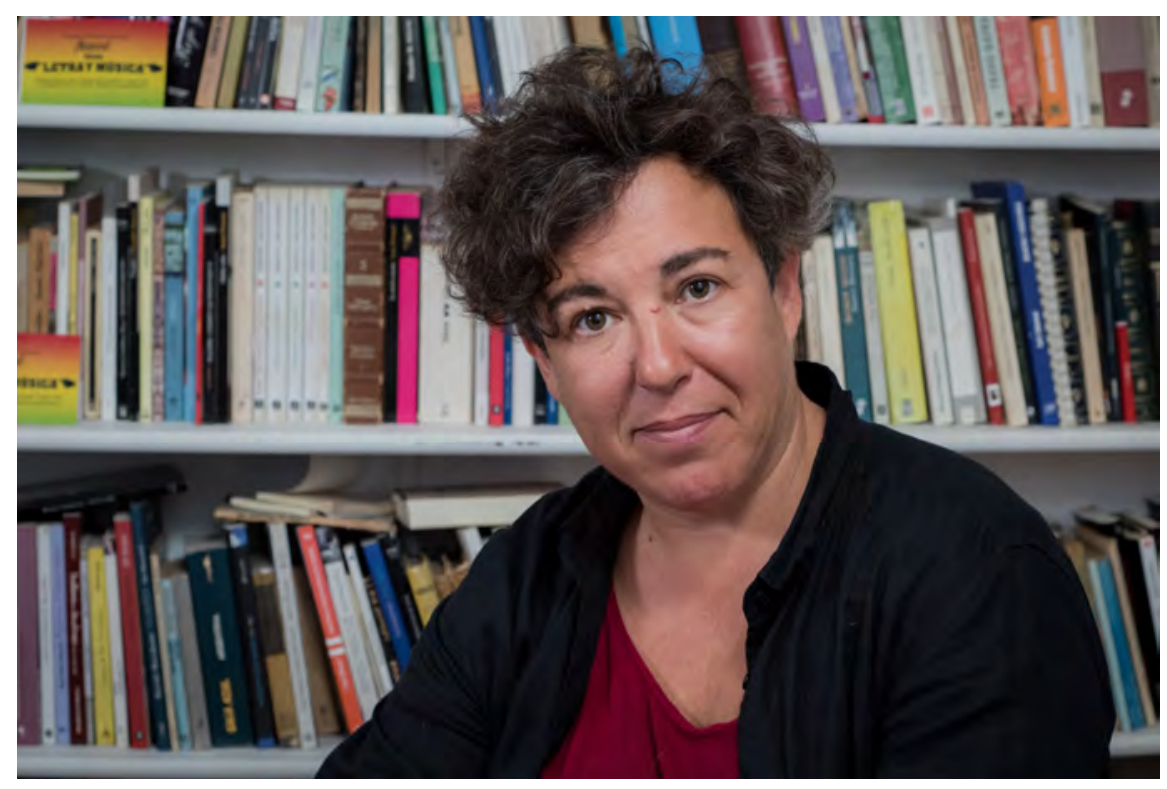




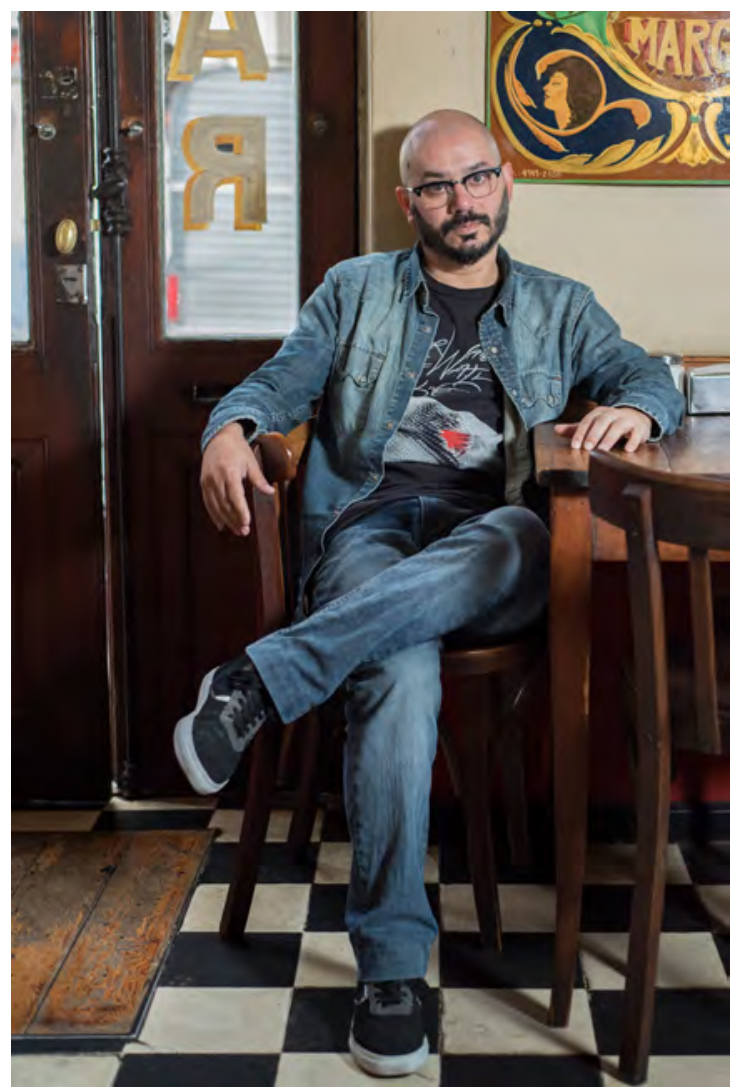

Juan Carrá

Es periodista y escritor. Nació en Mar del Plata el 18 de marzo de 1978 y actualmente reside en Buenos Aires. Fue distinguido por la Secretaría de Cultura de la Municipalidad de General Pueyrredon con el Premio Alfonsina, con el rubro de Creación Literaria. Publicó Lloran mientras mueren (Vestales, 2016), Lima, un sábado más (Vestales, 2014), Criminis Causa (LS, 2013) y cuentos en diversas antologías. Es docente de la carrera de Escritura Creativa en la UNA (Universidad Nacional de las Artes) y de periodismo en el TEA (Taller Escuela Agencia).

Mi llegada al género negro está relacionada con mi trabajo como cronista de Policiales sumado a la lectura voraz de ciertos autores que me acercaron a una forma de decir, de contar historias que ponen en foco personajes y tramas que posibilitan mostrar universos ficcionales complejos capaces de permear una fuerte crítica al capitalismo. La novela negra policial ha ido mutando y hay quienes dicen que es el género por excelencia para contar las desigualdades y yo creo que en ese sentido es inagotable. Y que en todo caso va modificándose y poniendo en foco las formas del delito que emergen en cada región. Es la realidad la que nos da la posibilidad de contar nuestras historias, pero a través de universos ficcionales en los que, muchas veces, queda más en relieve el conflicto. (Juan Carrá) 


\section{Martín Sancia Kawamichi}

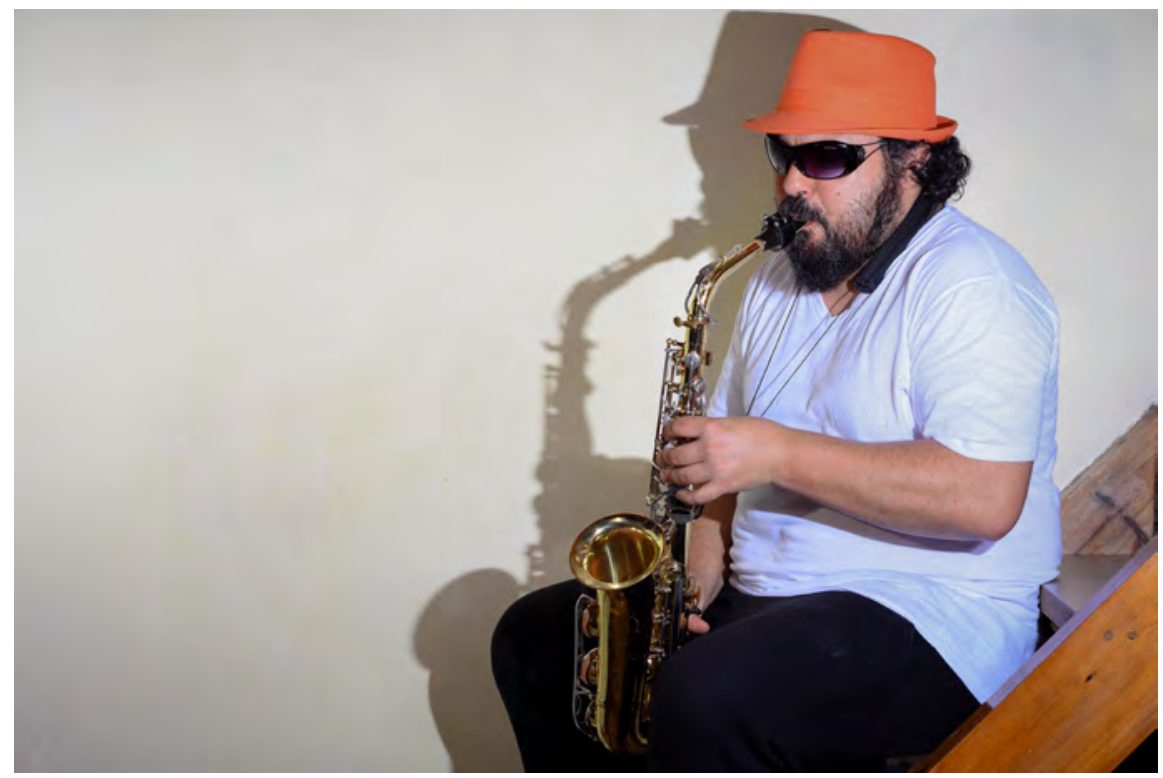

Nació en Buenos Aires en 1973. Estudió el Profesorado de Literatura y Latín en el Instituto Alicia Moreau de Justo, y Realización Cinematográfica en el Cievyc. Publicó, como Martín Sancia, tres libros que pertenecen al género infantil: Breves historias de animales sabrosos, engreídos, enamorados, malditos, venenosos, enlatados, tristes, cobardes, crueles, espinosos... (y otras historias) (2009, Editorial Sudamericana), Los poseídos de Luna Picante (Segundo Premio Sigmar de Literatura Infantil y Juvenil 2014) y 25 tarántulas (2016, Editorial Sigmar). Participó en el libro Cuentos policiales para niños (2015, Ediciones Lea). Fuera del género infantil, su novela Hotaru, firmada solo con sus dos apellidos, Sancia Kawamichi, obtuvo el Primer Premio del Concurso de Novela Negra BAN! - Extremo Negro, en el 2014.

Pienso que tenés que ser un escritor de una gran solidez para manejarte en un género plagado de trampas sin caer en ninguna. Supongo que, si querés escribir una novela negra, el mayor desafío que tenés por delante es ese: que el género no te termine pasando por encima. Y si no, como es mi caso, lo que te queda es moverte a un costado de las convenciones genéricas, eludiendo las trampas desde lejos, mirando el género desde una prudente distancia, sin embarrarte del todo, sin que nada te respire en la nuca. Que mi novela Hotaru no pueda encasillarse como una novela negra es una limitación, no un logro. Rehuir al encasillamiento es para los tibios, y yo, tanto por falta de recursos como de coraje, estoy condenado a esa tibieza. (Martín Sancia Kawamichi) 


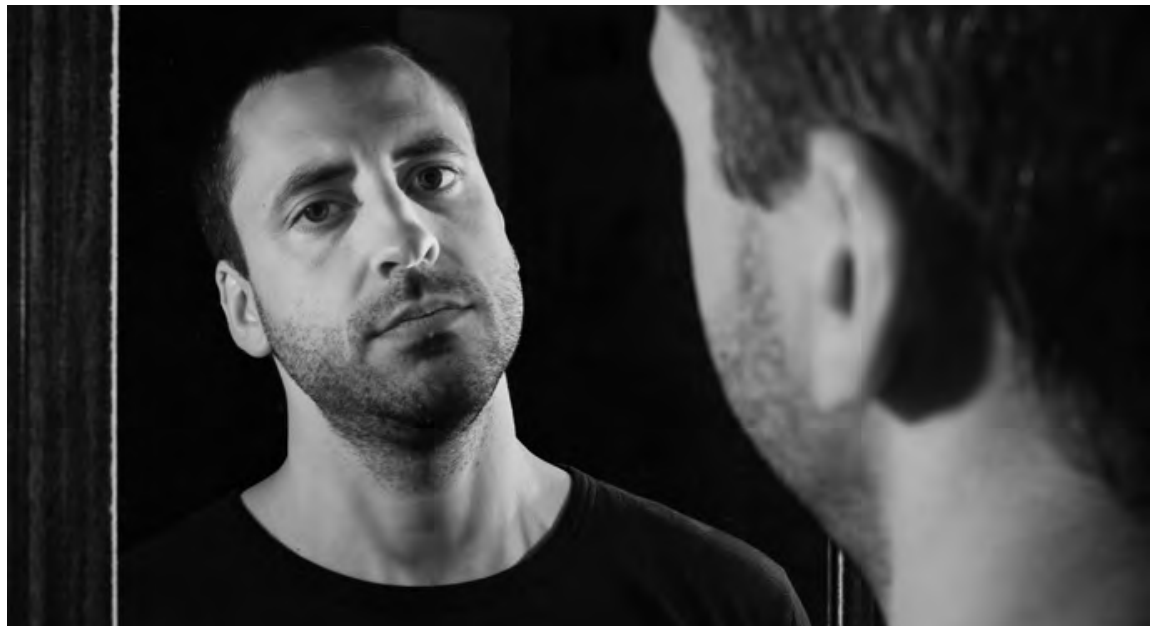

\section{Matías Bragagnolo}

Nació en la ciudad de La Plata en 1980. Se graduó de abogado en 2005, profesión que ejerce desde entonces. Su novela Petite mort, centrada en el mito del cine snuff, fue finalista de los concursos Laura Palmer no ha muerto (2010, Editorial Gárgola, Argentina) y BAN! - Extremo Negro (2013), y fue publicada en Argentina en 2014, y en España en 2015 por el sello Extremo Negro del grupo editorial Del Nuevo Extremo. Su segunda novela, El brujo, ambientada en una cárcel de máxima seguridad, fue publicada en 2015 también por Extremo Negro. Es autor de numerosos cuentos y poemas que han sido publicados en revistas y antologías.

Considero a los géneros literarios meras formas de expresión, moldes en los que una historia determinada puede ser insertada para ser contada. Simplemente están ahí, y uno puede usarlos o no. Usar uno con exclusividad, usar todos aquellos que crea necesarios, amalgamados.

Pero es cierto que hasta que mis novelas fueron catalogadas dentro del género negro (un género dotado de amplitud y generosidad, hay que reconocer) yo no había dado demasiado valor a la función del género. Creo, aún hoy, que más importante a la hora de contar una buena historia es valorar aspectos como el estilo, las voces y la forma. Así, Petite mort toma el esquema de una novela detectivesca para contar una historia que poco tiene de detectivesca, alternando diferentes técnicas narrativas (desgrabación de una cinta, entrevistas, monografía, narración omnipresente, guión cinematográfico, etc.). En El brujo, el género negro viene apenas de la mano de la temática criminal y carcelaria: si me pongo a hilar fino, esquemáticamente veo a "Los 120 días de Sodoma", veo al ciberpunk, a las "rutinas" de W.S. Burroughs, al realismo delirante postulado por Laiseca... (Matías Bragagnolo) 


\section{Tatiana Goransky}

Nació en Buenos Aires en 1977. Es escritora, dramaturga y cantante de jazz. Escritora prolífera, empezó a publicar desde muy joven, y se dedicó a explorar diversos formatos y géneros. Comenzó trabajando para Uol, en su sección Uolsex, redactando reseñas de películas pornográficas y libros eróticos. Escribió la columna Séxodo (2000 / 2013). Colaboró en el diario Clarín y las revistas El Interpretador, Los Noveles, Lugares, El Planeta Urbano, Bacanal, Gabo, Contraseñas, Aerolíneas Argentinas, BA Mag, Agasex España y Suite, y con diversas publicaciones internacionales para las que escribió en inglés y en castellano. Publicó las novelas Lulúpe María T (Símurg), ¿Quién mató a la Cantante de fazz? (2008, Tantalia / Suburbano, Estados Unidos; Letra Sudaca / Cazador de Ratas, España), Don del agua (2010, Gárgola), Ball Boy (2013, Milena Caserola, El Octavo Loco), Los impecables (2016, Comba, España) y Fade Out (2016, Editorial Galerna).¿Quién mató a la Cantante de fazz? fue seleccionada por la Conabip para ser distribuida en más de mil bibliotecas populares, y la llevó a participar en los festivales de género negro de Medellín (Medellín Negro), Gijón (Semana Negra), Barcelona (BCNegra), Mar del Plata (Azabache) y Buenos Aires (B.A.N). Participó en las antologías La condición pornográfica (2011, El Cuervo, Bolivia), Hijas del horizonte (2015; compilada por Fernando Marías, España) y Ficciones súbitas (2014, Ediciones De Aquí a la Vuelta, Argentina). Se desempeña también como ghost writer de diversas figuras públicas y privadas.

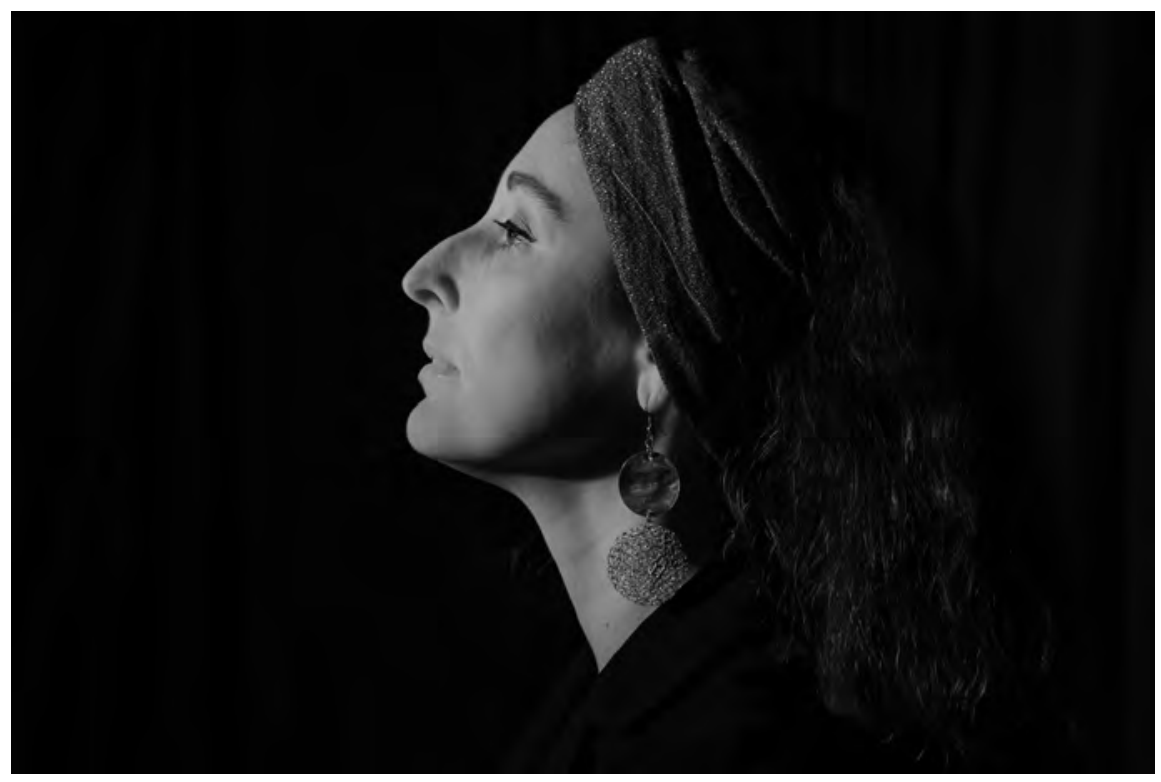




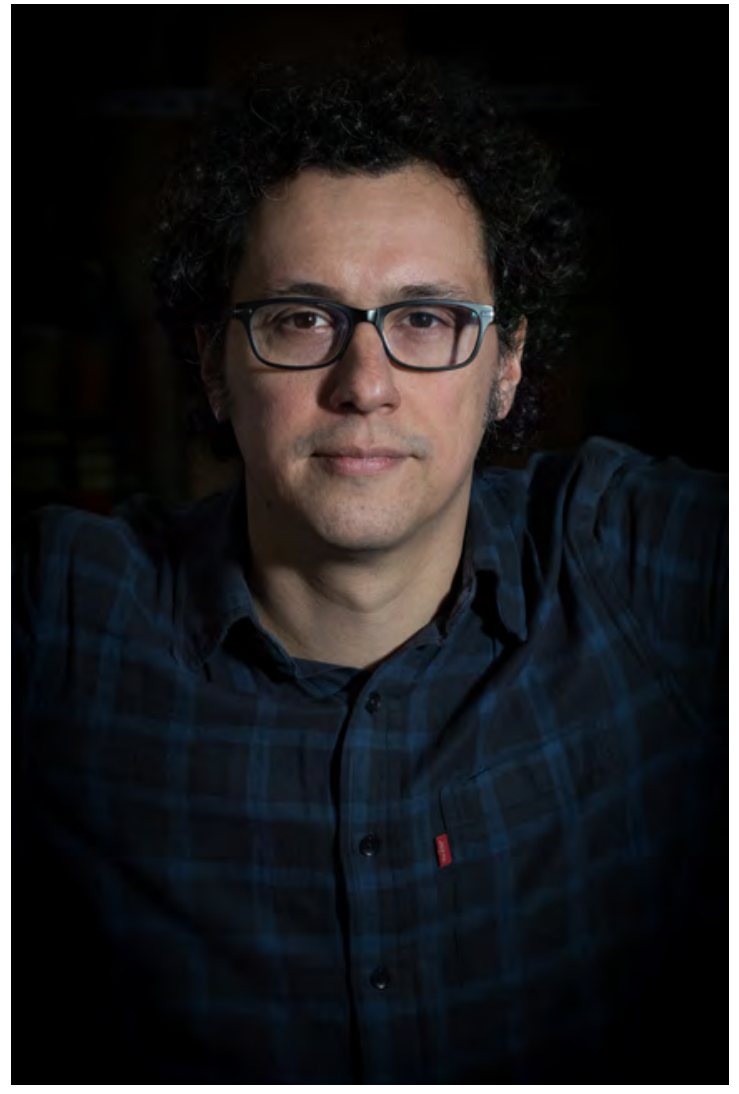

\section{Ricardo Romero}

Nació en Paraná, Entre Ríos, en 1976. Es Licenciado en Letras Modernas por la Universidad Nacional de Córdoba y desde 2002 vive en Buenos Aires. Fue director de la revista de literatura Oliverio entre 2003 y 2006. Entre el 2006 y el 2010 fue uno de los integrantes de El Quinteto de la Muerte, grupo con el cual editó los libros 5 (La Propia Cartonera, Uruguay) y La fiesta de la narrativa (Editorial Una Ventana, Buenos Aires). Tiene publicado el libro de cuentos Tantas noches como sean necesarias (2006) y las novelas Ninguna parte (2003), El síndrome de Rasputín (2008), Los bailarines del fin del mundo (2009), Perros de la lluvia (2011), El spleen de los muertos (2013), Historia de Roque Rey (2014) y La habitación del Presidente (2015). Es editor de Gárgola Ediciones, en donde dirige la colección Laura Palmer no ha muerto, y de Negro Absoluto, colección dirigida por Juan Sasturain. Ha sido traducido al portugués, al francés y al italiano. 